\title{
Удаление оксида с поверхности InP(001) в потоке мышьяка
}

\author{
Д.В. Дмитриев ${ }^{1}$, Д.А. Колосовский ${ }^{1,2}$, А.И. Торопов ${ }^{1}$, К.С. Журавлев ${ }^{1}$ \\ ${ }^{1}$ Институт физики полупроводников им. А.В. Ржанова СО РАН, Новосибирск, \\ 630090, пр. Лаврентьева, 13 \\ ${ }^{2}$ Новосибирский государственный университет, Новосибирск, 630090, Пирогова, 2 \\ тел:+7 (383) 330-6945, факс:+7 (383) 330-6945, эл.nочта: ddmitriev@isp.nsc.ru
}

DOI 10.34077/RCSP2021-94

Возможность создания в одном технологическом процессе гетероэпитаксиальных структур (ГЭС) для излучающих, передающих, модулирующих и принимающих элементов, делает InP ключевым материалом для интегральных систем радиофотоники $[1,2]$. Предэпитаксиальная термическая очистка подложек InP в сверхвысоком вакууме ростовой камеры в потоке мышьяка, позволяет получить резкую гетерограницу слой/подложка и избежать неконтролируемого встраивания фосфора в слои InAlAs/InGaAs, согласованные по параметру кристаллической решетки с подложкой [3]. Однако, в процессе отжига на поверхности формируются InAs островки, которые образуют дефекты на гетерогранице. Методом дифракции быстрых электронов на отражение (ДБЭО) in situ изучен процесс удаления оксида с поверхности epi-ready $\operatorname{InP}(001)$ подложки в потоке мышьяка в сверхвысоком вакууме.

Исследования проводились на установке МЛЭ Compact-21T фирмы Riber, оснащенной системой ДБЭО и системой анализа дифракционных картин kSA 400 фирмы k-Space Associates. Для отжига использовались epi-ready подложки $\operatorname{InP}(001)$ фирмы AXT. На рисунке представлено изменение интенсивности зеркального (00) и сверхструктурного (0 1/4) рефлексов. На вставке дифракционная картина сверхструктуры $(4 \times 2)$ в азимуте [110] при температуре $540^{\circ} \mathrm{C}$ и потоке мышьяка $2 \times 10^{5} \mathrm{Topp}$.

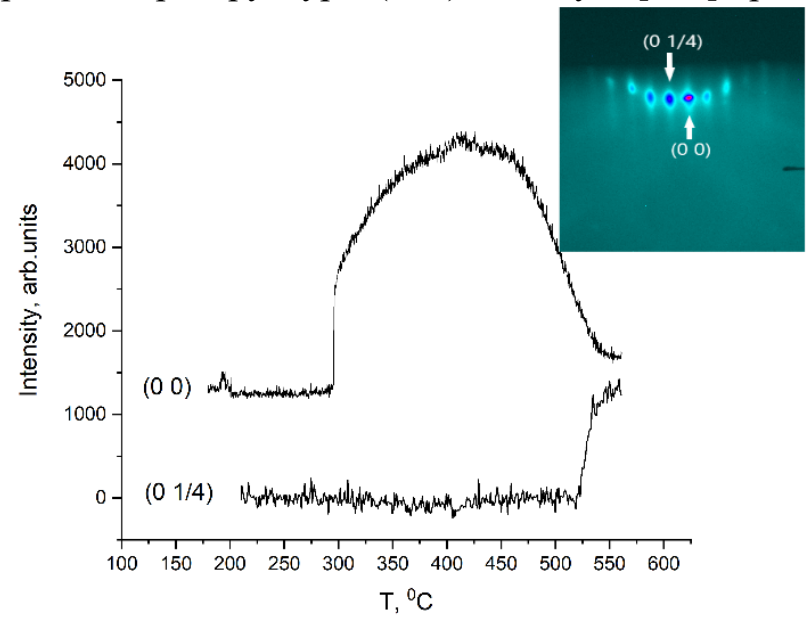
Принято считать, что появление сверхструктуры $(4 \times 2)$ означает завершение очистки поверхности InP от оксида. Однако, анализ изменения интенсивности (00) рефлекса, показывает: выше $300^{\circ} \mathrm{C}$ окисный слой утонялся, что проявлялось в увеличении интенсивности (00) рефлекса. При температуре $\sim 410{ }^{\circ} \mathrm{C}$ интенсивность выходила на максимальный уровень, что свидетельствует о получении максимально гладкой поверхности. Вероятно, при этой температуре основная часть оксида удалялась. Повышение температуры выше $480{ }^{\circ} \mathrm{C}$ приводит к уменьшению интенсивности зеркального (00) рефлекса, что говорит об увеличение рассеяния поверхности за счет увеличения шероховатости. Десорбция фосфора и мышьяка приводит к эрозии поверхности и появлению островков InAs. Переход в сверхструктуру (4x2) происходит при сформировавшемся на поверхности слое InPAs и InAs островках [4]. Наличие такого слоя может привести к формированию дефектов в последующих эпитаксиальных слоях.

В работе показано, что окисел с поверхности InP удаляется до появления сверхструктуры $(4 \times 2)$. Контроль интенсивность зеркального (00) рефлекса и завершение отжига при максимальной его интенсивности, позволит уменьшить плотность дефектов сформированных на гетерогранице слой/подложка.

Исследование выполнено при финансовой поддержке РФФИ и правительства Новосибирской области в рамках научного проекта № 20-42-540009.

\section{Лumepamypa}

[1] R. Nagarajan, et al. // IEEE J. Sel. Topics Quantum Electron. 2010. V.16. P.1113-1125.

[2] M. Smit, et al. // APL Photonics. 2019. V.4. P.050901.

[3] D.V. Dmitriev, et al. // IOP Conf. Ser.: Mater. Sci. Eng. 2019. V.475. P.012022.

[4] D.V. Dmitriev, et al. // Surface Science. 2021. V. 710. P. 121861. 